\section{AB0709 INFLUENCE OF DIETETARY INTAKES ON SPONDYLOARTHRITIS : AN OBSERVATIONAL PROSPECTIVE STUDY}

Kathy Nguyen, Pascale Vergne-Salle, Anne-Catherine Fressinaud-Marie, Philippe Bertin. University Hospital Limoges Dupuytren Hospital, Limoges, France

Background: Dysbiosis can be found in inflammatory joint diseases and induces alterations of the protective function of the intestinal barrier (1) Yet intestinal inflammation exists in ankylosing spondylitis, which is as much severe as the disease is active (2). Benefits of diets and their influence on the microbiota diversity and inflammation deserve to be studied in spondyloarthritis.

Objectives: The aim of the study was to investigate the nutritional profil in active spondyloarthritis.

Methods: An observational prospective monocentric study based in a french rheumatology department based in Limoges was conducted between February and July 2018, demographic and disease data were collected, in addition to the treatments and the food frequency questionnaire. Voluntary patients over 18 years of age with spondyloarthritis defined by ASAS classification were included. Patients with a diagnosis of inflammatory bowel disease or a bariatric surgery history were excluded of the study. The primary outcome was the correlation between omega-3, vitamin $\mathrm{C}$, refined sugars, fibers and ultra-processed food intakes and the disease activity assessed by ASDAS CRP and BASDAI scores.

Results: Among 140 patients included, there was no statistically significant difference in omega-3, vitamin C, refined sugars, fibers or ultra-processed food intakes between patients with active spondyloarthritis (BASDAI $\geq 4$ or ASDAS CRP $\geq 1,3$ ) and very active (ASDAS $\geq 2,1$ ) and patients with unactive disease. The quality of life score and fatigue score were more important in the active and very active disease forms, likewise for the digestive symptoms but there was no link founded in the different nutrients intakes, neither with the associated treatment.

Conclusion: Althouth our study did not find any nutritional profil in active spondyloarthritis, there was an alteration of quality of life and more digestive symptoms in the active group. Future researches are however required to explore the impact of dietatary intakes on the disease activity of spondyloarthritis.

\section{REFERENCES}

[1] Costello M-E, Robinson PC, Benham H, Brown MA. The intestinal microbiome in human disease and how it relates to arthritis and spondyloarthritis. Best Pract Res Clin Rheumatol. Avr 2015;29(2):202-12

[2] Hascelik G, Oz B, Olmez N, Memis A, Yoruk G, Unsal B, et al. Association of macroscopic gut inflammation with disease activity, functional status and quality of life in ankylosing spondylitis. Rheumato Int. mai 2009;29 (7):755-81)

Disclosure of Interests: None declared

DOI: 10.1136/annrheumdis-2019-eular.5114

\section{AB0710 IXEKIZUMAB SIGNIFICANTLY IMPROVES SELF- REPORTED OVERALL HEALTH AS MEASURED BY SF- 36 IN PATIENTS WITH ACTIVE ANKYLOSING SPONDYLITIS/RADIOGRAPHIC AXIAL SPONDYLOARTHRITIS NAIVE TO BIOLOGICAL THERAPY: 52 WEEK RESULTS OF A PHASE 3 TRIAL}

James Cheng-Chung Wei ${ }^{1}$, Filip van den Bosch ${ }^{2}$, Jessica A. Walsh ${ }^{3,4}$, Uta Kiltz ${ }^{5,6}$, Theresa Hunter ${ }^{7}$, Yan Dong ${ }^{7}$, Ann Leung ${ }^{8}$, David Sandoval ${ }^{7}$, Luis Leon ${ }^{7}$, Vibeke Strand ${ }^{9} .{ }^{1}$ Chung Shan Medical University Hospital, Taichung City, Japan; ${ }^{2}$ Ghent University Hospital, Ghent, Belgium; ${ }^{3}$ University of Utah School of Medicine, Salt Lake City, United States of America; ${ }^{4}$ Veterans Affairs Medical Center, Salt Lake City, United States of America; ${ }^{5}$ Rheumazentrum Ruhrgebiet, Herne, Germany; ${ }^{6}$ Ruhr-Universität Bochum, Bochum, Germany; ${ }^{7}$ Eli Lilly and Company, Indianapolis, United States of America; ${ }^{8}$ Syneos Health, Raleigh, United States of America; ${ }^{9}$ Biopharmaceutical Consultant, Portola Valley, United States of America

Background: Using the Short-Form-36 (SF-36) questionnaire, previous studies have determined that ankylosing spondylitis/radiographic axial spondyloarthritis (AS/r-axSpA) significantly impairs patients' health-related quality of life (HRQoL). ${ }^{1}$ Ixekizumab (IXE), a humanized anti-interleukin$17 \mathrm{~A}$ monoclonal antibody, improves disease signs and symptoms in patients with $\mathrm{AS} / \mathrm{r}$-axSpA. ${ }^{2}$

Objectives: To quantify the effect of 52 weeks of IXE treatment on selfreported HRQoL in patients with active AS/r-axSpA who are naïve to biologic therapy (NCT02696785).
Methods: COAST-V is a randomized, double-blind clinical trial that is active- and placebo-controlled in its first 16 weeks. Enrolled patients were adults with active $A S / r-a x S p A$ with ASAS criteria who fulfilled $\mathrm{mNY}$ of sacroilitis (central reading), with a BASDAI and back pain $\geq 4$, and with no prior treatment with biologic agents. Patients were initially randomized 1:1:1:1 to $80 \mathrm{mg}$ IXE every 4 weeks (Q4W) or every 2 weeks (Q2W), adalimumab (ADA), or placebo (PBO) groups. Changes from baseline in SF-36 up to Week 16 were analyzed by mixed model for repeated measures. Changes from baseline in SF-36 for Weeks 36-52 had no model applied. Missing data were imputed by modified baseline observation carried forward (mBOCF).

Results: By Week 4, statistically significant differences in Physical Component Summary (PCS) were observed between PBO and both IXE Q4W and Q2W groups (Figure; $\mathrm{p} \leq 0.002$ ). Further differences in PCS between PBO and IXE groups were observed up to 16 weeks $(\mathrm{p}<0.001)$ and maintained through 52 weeks. The change in Mental Component Summary (MCS) was modest (Table). Improvements in all domains were reported at 52 weeks for both the Q4W and Q2W doses of IXE, with the largest improvements observed in the bodily pain domain (Table). Conclusion: Improvement in self-reported HRQoL in patients with $A S / r-$ axSpA as measured by SF-36 was observed as soon as Week 4 of IXE treatment and maintained for at least 52 weeks.

Figure. SF-36 Physical Component Summary Mean Change from Baseline.

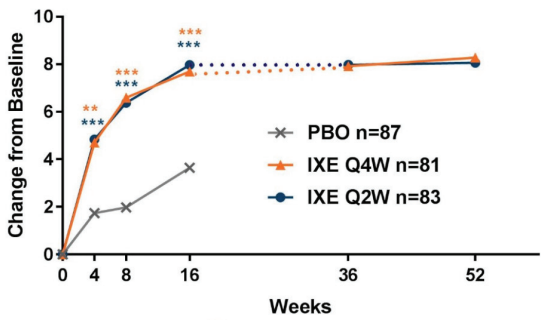

** $p=0.002$ IXE Q4W vs. PBO; *** $p<0.001$ IXE Q4W vs. PBO, ${ }^{* * *} p<0.001$ IXE Q2W vs PBO

Dotted lines indicate different analyses were performed at Weeks $4-16$ compared to Weeks $36-52$. For Weeks 4-16, change from baseline was estimated by mixed model for Tocks 36 -52. For wor reated measures. For Weeks $36-52$, obsenved change from baseline is presented with no model applied, and missing data was imputed by modified baseline observation carried

\section{REFERENCES}

[1] Yang, et al. (2016). Qual Life Res. 25:2711-23.

[2] van der Heijde, et al. (2018). Lancet. 392(10163):2441-51.

Table: SF-36 Baseline Scores and Mean Change at Week 52

\begin{tabular}{|c|c|c|c|c|}
\hline & \multicolumn{2}{|c|}{ IXE Q4W (n=81) } & \multicolumn{2}{|c|}{ IXE Q2W (n=83) } \\
\hline & Baseline & $\begin{array}{c}\text { Mean } \Delta \text { at Week } \\
52\end{array}$ & Baseline & $\begin{array}{c}\text { Mean } \Delta \text { at Week } \\
52\end{array}$ \\
\hline $\begin{array}{l}\text { Physical Component } \\
\text { Summary }\end{array}$ & 36.4 & 8.3 & 36.6 & 8.1 \\
\hline $\begin{array}{l}\text { Mental Component } \\
\text { Summary }\end{array}$ & 50.7 & 2.2 & 46.9 & 4.5 \\
\hline Domains: & & & & \\
\hline Physical Function & 39.2 & 7.0 & 38.1 & 8.0 \\
\hline Role-Physical & 39.3 & 6.9 & 38.6 & 6.7 \\
\hline Bodily Pain & 36.7 & 9.7 & 36.4 & 9.3 \\
\hline General Health & 41.8 & 4.2 & 40.2 & 5.8 \\
\hline Vitality & 45.9 & 6.1 & 44.9 & 6.9 \\
\hline Social Functioning & 46.2 & 4.1 & 42.9 & 6.0 \\
\hline Role-Emotional & 46.2 & 4.3 & 43.3 & 5.0 \\
\hline Mental Health & 48.2 & 2.5 & 44.4 & 5.7 \\
\hline
\end{tabular}

SF-36=Short-Form-36 Questionnaire; IXE Q2W=IXE dosed every 2 weeks; IXE Q4W=IXE dosed every 4 weeks; $n=$ number of patients in analysis population; Mean $\Delta=$ mean change from baseline value with $\mathrm{mBOCF}$.

Disclosure of Interests: James Cheng-Chung Wei Grant/research support from: Abbvie, BMS, Celgene, Janssen, Novartis, Pfizer, and UCB pharma, Consultant for: TSH Taiwan, Speakers bureau: Janssen, Novartis, Pfizer and TSH, Filip van den Bosch Consultant for: AbbVie, BMS, Galapagos, Janssen, Lilly, Merck, Novartis, Pfizer and UCB, Speakers bureau: AbbVie, BMS, Janssen, Lilly, Merck, Novartis, Pfizer and UCB., Jessica A. Walsh Grant/research support from: Abbvie, Pfizer, Consultant for: Abbvie, Celgene, Lilly, Novartis, Uta Kiltz Grant/research support from: AbbVie, 